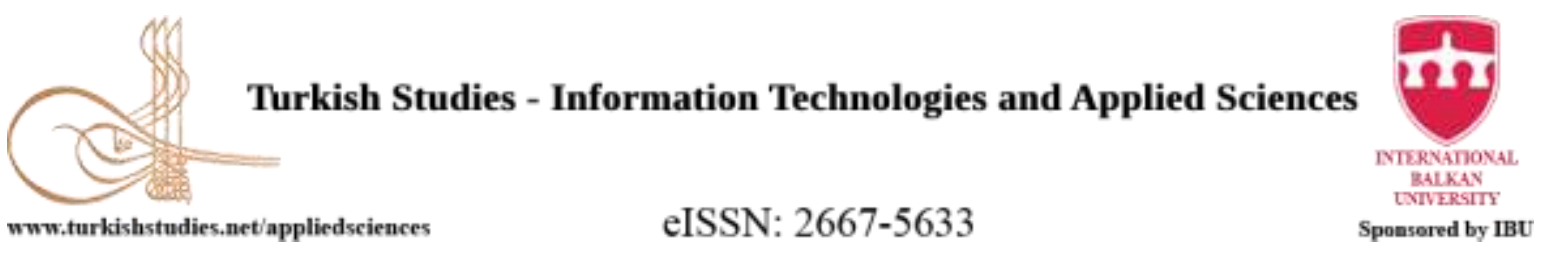

Research Article / Araştırma Makalesi

\title{
Dijital Okuryazarlık Dersini Uzaktan Eğitim Yöntemiyle Alan Öğrencilerin E-Öğrenmeye Yönelik Tutumları
}

\author{
Attitudes of Students Taking Digital Literacy Course Through Distance Education Towards \\ E-Learning
}

\author{
Ömer Bilen* - Abdullatif Kaban**
}

\begin{abstract}
Today, it is seen that higher education institutions have entered the digital transformation process and want to provide their students with digital literacy experience. In order to contribute to the successful completion of this transformation, there is a need to determine the attitudes of students towards e-learning. Pilot implementations by the Council of Higher Education are seen as an opportunity to benefit from the experiences gained from digital literacy courses. In this study, it was aimed to determine the attitudes of students taking digital literacy course with distance education towards e-learning and to examine them in terms of independent variables. For this purpose, in this study, the survey model, one of the quantitative research methods, was used. The data of the research were collected by using the e-learning attitude scale applied to students who took the digital literacy course in Bayburt University in the Spring semester of 2018 - 2019 academic year. The data obtained were analyzed using the SPSS program and the necessary statistical results were edited. As a result of the analysis, it was concluded that the attitudes of students who took the digital literacy course towards e-learning were at a medium level. It was determined that the gender of the participants, the department they are affiliated with, and the digital literacy course midterm exam grade affect the attitude towards e-learning. In addition to this result, it was observed that the grade level and the overall weighted average did not affect the attitude. In line with the results obtained, it has been suggested that other courses can be given by distance education for students who will take the digital literacy course. It is thought that the results obtained will contribute to universities and digital literacy course content planners who are experiencing digital transformation.
\end{abstract}

Structured Abstract: Developments in information and communication technologies have profoundly affected people's education, relationships, communications, socialization processes and lifestyles. Internet, wireless network technologies, smart phones, tablets, laptop computers and similar mobile communication tools are at the center of this change that takes place today. Digital literacy defined as the ability to survive in

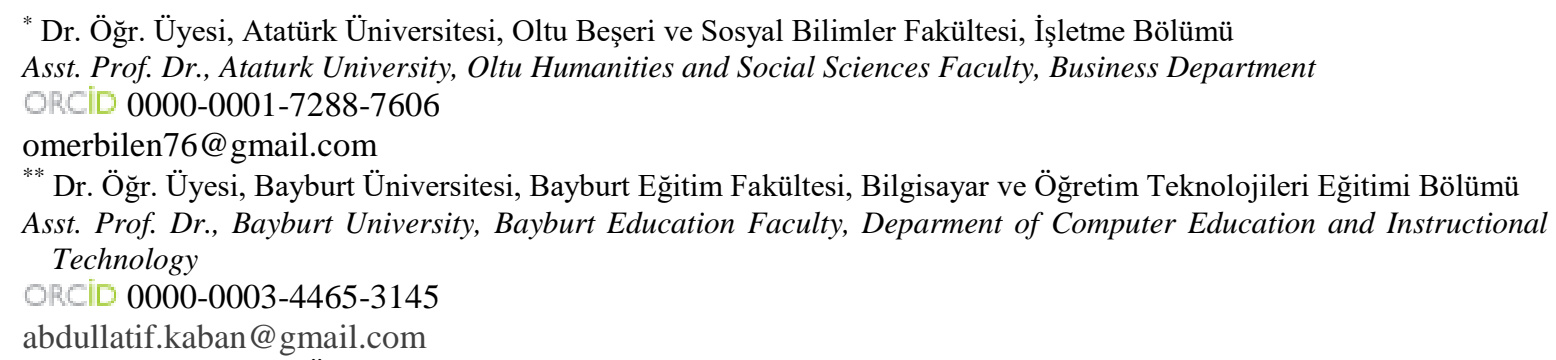

abdullatif.kaban@gmail.com

Cite as/ Atıf: Bilen, Ö. \& Kaban, A. (2020). Dijital Okuryazarlık dersini uzaktan eğitim yöntemiyle alan öğrencilerin E-öğrenmeye yönelik tutumları. Turkish Studies - Applied Sciences, 15(3), 389-400. https://dx.doi.org/10.47844/TurkishStudies.44914

Received/Geliş: 07 July/Temmuz 2020

Accepted/Kabul: 20 September/Eylül 2020

Copyright (C) INTAC LTD, Turkey 
the digital age is an indicator of students quality of work in digital environments (Eshet-Alkalai, 2004), a change of mindset (Gilster, 1997), recognizing, accessing, managing, evaluating, analyzing and synthesizing digital tools and digital resources. One of the most important elements that make digital transformation almost compulsory is the changing student profile. Younger generations spend most of their time with computers and mobile devices, which are indispensable communication tools of the information age. In order to ensure digital transformation, all education stakeholders, primarily managers, should have the infrastructure to be ready for this transformation (Balyer \& Öz, 2018). In order to obtain the desired efficiency from e-learning, studies on learners in this way are of great importance in the literature. While researchers mostly advocate that the quality of education will increase thanks to the driving force of technology, Gefen \& Straub (1997) expressed the view that the factor that will increase the quality in education is not technology, and that users have positive attitudes towards technology (Krishnakumar \& Kumar, 2011).

It is known that a student must have a positive attitude towards a subject in order to be successful in that subject. (Karasakaloğlu \& Saracaloğlu, 2009). In these days when digital transformation is rapidly spreading, it is expected that students' attitudes towards e-learning will be determined and they will benefit from the experiences gained from digital literacy courses piloted by Council of Higher Education. It is thought that the e-learning experiences of the students who took the digital literacy course through distance education affect the attitudes of the students. In this process, it is considered that it will be appropriate to determine the current situation and determine the needs and, if necessary, rearrange the content of the digital literacy course. In this study, it was aimed to determine the attitudes of students taking digital literacy course with distance education towards e-learning and to examine them in terms of independent variables.

In this study, which aims to determine the attitudes of students who take the digital literacy course with distance education to e-learning, the survey model, one of the quantitative research methods, was used. Students who took the digital literacy course both took the course with the method of distance education and gained knowledge about the e-learning included in the content of the course. The universe of the study is the students who study at Bayburt University and take the digital literacy course that is included in the curriculum in the Spring semester of 2018-2019 academic year. The sample of the study consists of 579 students selected among these students by the purposeful sampling method and voluntarily participated in the study. E-Learning Attitude Scale, which was developed by Wilkinson, Roberts and While (2010) and adapted to Turkish by Haznedar (2012), was used as the data collection tool used in the study. A few open-ended questions have been added to the data collection tool to obtain some demographic information of the students.

The attitudes of students who take the digital literacy course with distance education towards elearning are at the level of "I am indecisive". While an above-average attitude is expected from students who have received distance education, a medium level attitude shows that the goals of the received education are not reached at the expected level. As a result of the analysis, it was concluded that there is a statistically significant difference in students' attitudes towards e-learning and this difference is in favor of male students. A significant relation was also found between the departments of the students and the attitude towards elearning. It was concluded that Computer and Instructional Technology Education students have positive attitudes towards e-learning from other departments. Students attitude towards e-learning does not differ in terms of grade levels and general weighted grade point average. There is a positive relationship between midterm grades of digital literacy course and students' attitudes towards e-learning.

In line with the results obtained from the study, the following suggestions can be made. Supportive training and seminars can be given for students with a moderate attitude towards e-learning. In this study, only students' attitudes towards e-learning were investigated. Qualitative studies can be conducted on the experience of digital literacy lessons. In order to develop a positive attitude towards e-learning, courses with appropriate content in each program of higher education can be given by distance education.

Keywords: E-learning, attitude, digital literacy, digital transformation.

Öz: Günümüzde yükseköğretim kurumlarının dijital dönüşüm sürecine girdiği ve bu konuda öğrencilerine dijital okuryazarlık tecrübesi kazandırmak istediği görülmektedir. Bu dönüşümün başarıyla sonuçlanmasına katkı sağlamak amacıyla öğrencilerin e-öğrenmeye yönelik tutumlarının belirlenmesi ihtiyacı doğmaktadır. YÖK tarafından yapılan pilot uygulamalar, dijital okuryazarlık derslerinden edinilen tecrübelerden faydalanmak için bir firsat olarak görülmektedir. Bu çalışmada dijital okuryazarlık dersini uzaktan eğitimle 
alan öğrencilerin e-öğrenmeye yönelik tutumlarının belirlenmesi ve bağımsız değişkenler açısından incelenmesi amaçlanmıştır. Bu amaç doğrultusunda çalışmada nicel araştırma yöntemlerinden tarama modeli kullanılmıştır. Araştırmanın verileri, Bayburt Üniversitesinde 2018-2019 eğitim-öğretim yılı Bahar yarıyılında dijital okuryazarlık dersini uzaktan eğitimle alan öğrencilere uygulanan e-öğrenmeye yönelik tutum ölçeği kullanılarak toplanmıştır. Elde edilen veriler SPSS 22 programı kullanılarak analiz edilmiş ve gerekli istatistik sonuçları elde edilmiştir. Yapılan analiz sonucunda dijital okuryazarlık dersini uzaktan eğitimle alan öğrencilerin e-öğrenmeye yönelik tutumlarının orta seviyede olduğu sonucuna varılmıştır. Katılımcıların cinsiyetinin, bağlı bulundukları ana bilim dalının ve dijital okuryazarlık dersi ara sınav notunun e-öğrenmeye yönelik tutuma etki ettiği belirlenmiştir. $\mathrm{Bu}$ sonucun yanı sıra sınıf düzeyinin ve genel ağırlıklı not ortalamasının tutuma etki etmediği görülmüştür. Elde edilen sonuçlar doğrultusunda dijital okuryazarlık dersini alacak öğrencilere başka derslerin de uzaktan eğitimle verilebileceği önerisinde bulunulmuştur. Elde edilen sonuçların dijital dönüşüm süreci yaşayan üniversitelere ve dijital okuryazarlık dersi içerik planlayıcılarına katkı sağlayacağı düşünülmektedir.

Anahtar Kelimeler: Öğretim teknolojileri, e-öğrenme, tutum, dijital okuryazarlık, dijital dönüşüm

\section{Giriş}

Bilgi ve iletişim araçlarının zamanla gelişmesi insanoğlunun eğitim, ilişki, iletişim, sosyalleşme ve yaşam stillerini derinden etkilemiştir. Hâlihazırda ortaya çıan bu yenilenmenin odağında internet, cep telefonu, kablosuz cihazlar, tablet, dizüstü bilgisayar ve buna benzer mobil cihazlar bulunmaktadır. İnternet, McLuhan ve Powers'ın (2001) ifadesiyle dünyayı “Global Köy”e dönüştürmüş, dünyanın bir yerinde meydana gelen bir olayın kısa süre içerisinde dünyanın geri kalan kısmında duyulmasını sağlayan yeni bir dünya düzenini oluşturmuştur. $\mathrm{Bu}$ noktada taşınabilir iletişim cihazları insanın her an her yerde bilgiye erişmesini mümkün kılmaktadır. Castells (2005), günümüzde ortaya çıkan bu yeni toplumsal organizasyon türünü ağ toplumu olarak nitelendirmiştir. A $\breve{g}$ toplumunun en dikkat çeken niteliği, kablosuz ağ ve mobil iletişim teknolojileriyle zamansal ve uzamsal sinırlamaları tamamen ortadan kaldırmasıdır.

Özellikle İnternet teknolojilerinin ilerlemesiyle birlikte son yıllarda hayatımızın ayrılmaz bir parçası konumunda olan dijital teknolojiler gündelik yaşam deneyimlerimizi büyük oranda değiştirmiş̧ir (Demiral, 2018). Dijital kelimesi Latince digitus kelimesinden türetilmiştir. Türk Dil Kurumu (TDK) sözlüğü, dijital kelimesinin birinci anlamı için "sayısal" ve ikinci anlamı için ise "verileri bir ekran üzerinde elektronik olarak gösteren" karşılıklarını kullanmaktadır (TDK, 2020). Prensky (2001) bilgisayar, video oyunları ve internetin dilini anadili gibi konuşanlar için "dijital yerli”, bu teknolojiyle yetişmemiş ancak yaşamının bir bölümünde bu teknolojileri kullanma firsatı yakalamış ya da kullanmak zorunda kalmış olanlar için ise "dijital göçmen" ifadesini kullanmıştır. Dijital çağda yetişen kuşaklar üzerine araştırma yapan Tapscott (2009), X kuşağının 1976 doğumlulara kadar geldiği, 1977-1997 yılları arasında doğanların Y kuşağına dâhil olduklarını ve 1997'den sonra doğanları ise teknolojiyle şekillenen kuşak olarak tanımlamaktadır. Dijital çağın en önemli özelliklerinden biri dijital okuryazarlıktır.

Dijital okuryazarlığın ilkeleri ilk olarak Gilster (1997) tarafından belirlenmiştir. Bu ilkeler çeşitli yazılım ve donanımlara erişim ve bunları kullanmak için gereken bilgi ve beceriye sahip olmak, dijital ortamda paylaşılan içerikleri anlama ve analiz etmek için gerekli yeterliğe sahip olmak ve bu içerikleri dijital teknoloji ile oluşturma becerisine sahip olmak şeklinde sıralanabilir. Dijital okuryazarlık; dijital çağda hayatta kalma becerisi, öğrencilerin dijital ortamlardaki çalışma kalitesinin bir göstergesi (Eshet-Alkalai, 2004), bir zihniyet değişimi (Gilster, 1997), dijital araçların ve kaynakların farkında olmak, onlara erişmek, onları idare etmek, niteliğini ölçmek, analiz etmek ve gerektiğinde sentezlemek olarak tanımlanmıştır. Bir başka tanımda yeni bilgiyi türetmek, kitle iletişim ortamlarında başkalarıyla irtibat kurabilme tutumu ve yeteneği olarak ifade edilmiştir (Martin, 2005). Literatürde 21.yüzyıl becerileri olarak ifade edilen eleştirel düşünme becerileri olmadan sadece teknolojiyi, interneti veya sosyal medyayı iyi kullanmanın bir kullanıcıyı dijital

www.turkishstudies.net/appliedsciences 
okuryazar yapmadığı öne sürülmektedir (Duran \& Özen, 2018; Eshet, 2002). Dijital okuryazar olan bir birey aynı zamanda teknolojiyi kullanarak ihtiyaç duyduğu bilgiye ulaşabilen ve bu bilgiyle karşılaştığı problemi çözebilen ve kişisel gelişimini kendi başına yapabilen kişi olarak tanımlanmıştır (Acar, 2015). Eshet'e (2002) göre dijital okuryazarlık, özel bir düşünme şeklidir ve beraberinde internetten sadece bilgi toplamayı değil, ulaşılan verilerin nasıl kullanılacağını, doğru ve yanlış bilgi arasında tercih yapabilmeyi gerektirmektedir. Dijital okuryazar sayısını artırmanın yollarından biri, belki de en önemlisi, eğitim - öğretim ortamlarında dijital dönüşümü gerçekleştirmektir.

Dijital dönüşümü neredeyse zorunlu hale getiren unsurların başında öğrenci profili gelmektedir. Genç kuşaklar zamanlarının çoğunu bilgi çağının olmazsa olmaz iletişim araçları olan bilgisayarlar ve mobil cihazlarla geçirmektedir. Prensky (2001) dijital araçların içinde doğan çocukları "dijital yerliler" olarak nitelendirmiş ve bu çağda yetişen öğrencileri teknolojik ortamlarda konuşulan dijital terminolojiyi kendi ana dili gibi konuşan bireyler olarak görmüştür. Diğer bir tanımda dijital yerliler haberleşmede, etkinliklerde ve tecrübelerinde çoklu ortam araçlarını etkili bir şekilde kullanabilen, bilgiyi toplu bir şekilde edinmeyi, tecrübelerini sentezlemeyi, deneysel ve aktif öğrenme yöntemini seçen bir öğrenen topluluğu olarak ifade edilmiştir (Dede, 2005). Bu yönüyle yeni neslin, teknolojiye sürekli maruz kalmaları sebebiyle yani teknoloji tarafından kuşatılan bir dünyaya doğdukları için önceki nesillerle düşünce yapısı, hareket tarzı ve öğrenme şekli farklılaşmaktadır. Teknolojiyi yakından takip eden bu yeni neslin eğitim ihtiyaçlarını karşılamak amacıyla eğitim sistemi yeniden düzenlenmelidir. Bu yüzden dijital dönüşüm ve dijital okuryazarlık konusunda, ilköğretimden yükseköğretime kadar eğitimin her seviyesinde altyapı, insan kaynakları ve içerik gibi hususlarda çağdaş bir yapılandırmaya gidilmesi gerekmektedir (Karabacak \& Sezgin, 2019). Dijital dönüşüm sürecine ayak uydurmaya çalışan öğrencilerin iletişim, düşünme, bağımsız öğrenebilme, takım çalışması ve esneklik, etik ve sorumluluk ve ihtiyaç duyduğunda dijital aletleri kullanabilme gibi bazı becerilere sahip olması gerekmektedir (Bates, 2018). Eğitimde dijital dönüşümün başarılı bir şekilde gerçekleşmesi için eğitimin tüm paydaşlarına gereken teknik destek alt yapısı sunmak ve dönüşüm için ihtiyaç duyulacak eğitimi almalarını sağlamak gerekmektedir (Taşkıran, 2017). Dijital dönüşümün sağlanması için başta yöneticiler olmak üzere eğitim paydaşlarının tamamının bu dönüşüme hazır olacak alt yapıya sahip olmaları gerekmektedir (Balyer \& Öz, 2018). Ülkemizde, eğitimde dijital dönüşüm, yükseköğretim için Üniversite 4.0 olarak anlaşılmaktadır. Üniversite 4.0'dan bahsederken eğitimin yenilikçi ve ileri görüşlü politikalarla yönetilmesi demek olan Yenilikçi Yönetim ve Liderlik, bireylere zaman ve mekân konusunda esneklik sağlayan Hayat Boyu Öğrenme ve Destek Hizmetleri olmak üzere Üniversite 4.0'1n üç boyutundan söz etmek mümkündür (Yıld1z-Aybek, 2017). Hayat boyu öğrenmenin temeli teknolojideki ilerlemeler ve bunun sonucu olarak da bilginin zamandan ve mekândan bağımsız olarak uzaktan eğitim yoluyla sunulmasıdır.

Uzaktan eğitim, tüm dünyayı etkisi altına alan covid-19 virüs salgınında olduğu gibi, geleneksel öğrenme - öğretme yöntemlerindeki kısıtlamalar nedeniyle etkinliklerin sınıf ortamında yapılmasının mümkün olmadığı durumlarda, öğretmen ve öğrenciler arasında iletişim ve etkileşimin çeşitli ortamlar üzerinden yürütüldüğ̈̈ bir öğretim yöntemidir. Uzaktan eğitimin ilk uygulamaları açık öğretim şeklinde olmuştur. Açık öğretim bireye kendi kendine öğrenme firsatı vermekte, bireyin teknoloji kullanım becerilerini artırmakta ve böylece toplumun dijital dönüşümüne katk1 sağlamaktadır (Fırat \& Güney, 2020). Dolayısıyla günümüzde uzaktan eğitim uygulamalarının açık eğitim kaynakları üzerinden e-öğrenme biçiminde yaygınlık kazandığı görülmektedir (Demirel, 2009). Açık eğitim kaynakları, öğretim, öğrenim ve araştırma amacıyla kamuya açık ortamlarda sunulan ve başkalarının özgürce kullanmasına izin veren bir fikrî mülkiyet lisansı altında serbest bırakılan kaynaklardır (Atkins, Brown, \& Hammo, 2007). Açık eğitim kaynakları etkili insan işbirliğini ve bireysel gelişimi mümkün kılmakta önemli bir rol oynayan oldukça karmaşık ve sürekli gelişen bir sistemin parçasıdır (Tuomi, 2013). Dünyanın herhangi bir yerinden pratik bilgi edinme ve daha düşük bir eğitim maliyetine sahip olma firsatı sağladıkları için MOOC olarak bilinen kitlesel 
çevrimiçi açık kurslara duyulan ilgi sürekli olarak artmaktadır (Yakovenko, Kulumbetova, Subbotina, Zhanibekova, \& Bizhanova, 2019).

E-öğrenmeden arzu edilen verimin alınabilmesi için bu yolla öğrenenler üzerinde yapılan çalışmalar büyük önem arz etmektedir. Yapılan araştırmalar e-öğrenmenin öğrencilerin derse aktif katılımını sağlayarak performanslarını artırdığını ve daha kalıcı öğrenmeler gerçekleştirmelerini sağladığını göstermektedir (Clark, 2002). Araştırmacılar çoğunlukla teknolojinin itici gücü sayesinde eğitimin niteliğinin artacağını savunurken, Gefen \& Straub (1997) ise eğitimde niteliği artıracak unsurun teknoloji olmadığını, teknolojiye karşı kullanıcıların olumlu tutumlara sahip oldukları görüşünü dile getirmişlerdir (Krishnakumar \& Kumar, 2011).

Öğrencinin bir konuda başarılı olabilmesi için o konuya yönelik olumlu tutuma sahip olması gerektiği bilinmektedir (Karasakaloğlu \& Saracaloğlu, 2009). Dijital dönüşümün hızla yayıldığı bu günlerde öğrencilerin e-öğrenmeye yönelik tutumlarının belirlenmesi ve YÖK tarafından pilot uygulaması yapılan dijital okuryazarlık derslerinden edinilen tecrübelerden faydalanılması beklenmektedir. Dijital okuryazarlık dersini uzaktan eğitimle alan öğrencilerin yaşamış oldukları eöğrenme tecrübelerinin öğrencilerin tutumlarını etkilediği düşünülmektedir. Bu süreçte mevcut durumun tespit edilerek ihtiyaçların belirlenmesi ve gerekirse dijital okuryazarlık dersinin içeriğinin

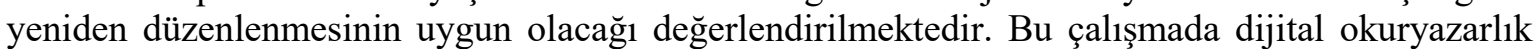
dersini uzaktan eğitimle alan öğrencilerin e-öğrenmeye yönelik tutumlarının belirlenmesi ve bağımsız değişkenler açısından incelenmesi amaçlanmıştır. Bu amaç doğrultusunda aşağıdaki araştırma sorularına yanıt aranmaktadır:

1. Dijital okuryazarlık dersini uzaktan eğitimle alan öğrencilerin e-öğrenmeye yönelik tutumları nasıldır?

2. Dijital okuryazarlık dersini uzaktan eğitimle alan öğrencilerin e-öğrenmeye yönelik tutumlar1

a) cinsiyet açısından,

b) ana bilim dalı açısından,

c) sınıf düzeyi açısından farklılaşmakta mıdır?

3. Dijital okuryazarlık dersini uzaktan eğitimle alan öğrencilerin e-öğrenmeye yönelik tutumlarina

a) genel not ortalamalarının,

b) bu dersin ara sınavından almış oldukları notun bir etkisi var mıdır?

\section{Yöntem}

Dijital okuryazarlık dersini uzaktan eğitimle alan öğrencilerin e-öğrenmeye yönelik tutumlarının belirlenmesinin amaçlandığı bu çalışmada, nicel araştırma yöntemlerinden tarama modeli kullanılmıştır. Tarama araştırmaları, daha önce gerçekleşen veya günümüzde var olan bir durumun kendi şartları içerisinde olduğu gibi betimlendiği çalışmalardır (Metin, 2015). Dijital okuryazarlık dersini uzaktan eğitimle alan öğrenciler hem dersi uzaktan eğitim yöntemiyle almışlar hem de dersin içeriğinde yer alan e-öğrenme ile ilgili bilgi sahibi olmuşlardır. Bu açıdan bakıldığında öğrencilerin e-öğrenmeye karşı tutumlarındaki mevcut durumlarının ortaya konulması amaciyla tarama modelinin kullanılmasına karar verilmiştir.

\section{Evren ve Örneklem}

Çalışmanın evrenini Bayburt Üniversitesinde öğrenim gören ve 2018-2019 eğitim-öğretim yılı Bahar yarıyılında müfredata dâhil olan dijital okuryazarlık dersini uzaktan eğitimle alan öğrenciler oluşturmaktadır. Çalışmanın örneklemini ise bu öğrenciler arasından amaçlı örnekleme yöntemi ile seçilen ve çalışmaya gönüllü olarak katılan 579 öğrenci oluşturmaktadır. 
Tablo 1: Katılımcıların ana bilim dalı ve cinsiyete göre dağılımları

\begin{tabular}{lcccc}
\hline Ana Bilim Dalı̈ & Kadın & Erkek & Toplam & Yüzde \\
\hline Bilgisayar ve Öğretim Teknolojileri Eğitimi & 15 & 17 & 32 & $5.5 \%$ \\
Fen Bilgisi Eğitimi & 62 & 24 & 86 & $14.9 \%$ \\
Yabancı Dil Eğitimi & 26 & 13 & 39 & $6.7 \%$ \\
Matematik Eğitimi & 34 & 25 & 59 & $10.2 \%$ \\
Rehberlik ve Psikolojik Danışmanlık & 83 & 43 & 126 & $21.8 \%$ \\
Sinıf Eğitimi & 75 & 38 & 113 & $19.5 \%$ \\
Sosyal Bilgiler Eğitimi & 39 & 24 & 63 & $10.9 \%$ \\
Türkçe Eğitimi & 38 & 23 & 61 & $10.5 \%$ \\
\hline Toplam & 372 & 207 & 579 & $100.0 \%$ \\
\hline
\end{tabular}

\section{Verilerin Toplanması}

Çalışma kapsamında kullanılan veri toplama aracı olarak Wilkinson, Roberts ve While (2010) tarafından geliştirilen bilgi iletişim teknolojileri becerileri, deneyimi ve e-öğrenmeye yönelik tutum ölçeğinin Haznedar'ın (2012) yüksek lisans tezi kapsamında Türkçeye uyarladığı E-Öğrenmeye Yönelik Tutum Ölçeği kullanılmıştır. Ölçek 20 sorudan oluşan 5'li likert yapıya sahiptir. Her bir sorunun değerini ölçmek için "Kesinlikle Katılmıyorum", "Katılmıyorum", "Kararsızım", "Katıllyorum" ve "Kesinlikle Katılıyorum” seçenekleri kullanılmıştır. Ölçekle birlikte öğrencilerin bölüm, sınıf, cinsiyet, genel not ortalaması ve dijital okur-yazarlık dersi ara sınav notunu almak üzere açık uçlu sorular sorulmuştur.

\section{Verilerin Analizi}

Verilerin analizinde SPSS 22 programı kullanılmıştır. Yapılacak analizlerin belirlenmesi için normallik testi yapılmıştır. Normallik testi yapmadan önce E-öğrenmeye yönelik tutumların ölçüldügü ankette bulunan olumsuz maddelere verilen puanlar ters çevrilmiştir. Yapılan normallik testinin sonucu Tablo 2'de verilmektedir.

Tablo 2: Normallik Testi

\begin{tabular}{cccccccc}
\hline & \multicolumn{3}{c}{ Kolmogorov-Smirnov } & \multicolumn{3}{c}{ Shapiro-Wilk } \\
\cline { 2 - 7 } & İstatistik & df & $\mathrm{p}$ & İstatistik & df & $\mathrm{p}$ \\
\hline Tutum Ortalamas1 & .058 & 579 & .000 & .993 & 579 & .007 \\
\hline
\end{tabular}

Yapılan normallik testi sonucu anlamlı bulunduğundan verilerin normal dağılmadığ görülmektedir. Ancak Tablo 3'te verilen tanımlayıcı istatistik verilerine bakıldığında çarpıklık (0.150) ve basıklık (0.123) değerlerinin Tabachnick ve Fidell (2013)'e göre -1.5 ile +1.5 değerleri arasında, George ve Mallery (2010)'a göre -2 ile +2 arasında olması normal dağılım olarak kabul edilmektedir.

Tablo 3: Tanımlayıcı istatistikler

\begin{tabular}{lcc}
\hline & İstatistik & Std. Sapma \\
\hline Ortalama & 3,0300 & .03191 \\
Çarpıklık & -.150 & .102 \\
Basıklık & .123 & .203 \\
\hline
\end{tabular}

Verilerin normal dağılım gösterdiği kabul edilerek e-öğrenmeye yönelik tutuma farklı değişkenlerin etkisini incelemek amaciyla, parametrik testlerden t-testi ve varyans analizi yapılmıştır. Bağımsız değişkenlerden iki grubun karşılaştırılmasında bağımsız örneklemler için ttesti, ikiden fazla grubun karşılaştırılmasında tek yönlü varyans analizi kullanılmıştır. Varyans analizi sonucunda gruplar arasında anlamlı bir farklılık bulunmuşsa, farklılığın hangi gruplar arasında olduğunun belirlenmesi için Post Hoc çoklu karşılaştırma testi yapılmıştır. Çoklu 
karşılaştırma testlerinden hangisinin yapılacağına karar vermek için Levene Testi ile varyansların homojenliği kontrol edilmiş ve varyans eşitsizliği durumunda Post Hoc testinden Dunnett's C seçilerek anlamlı farklılıklara bakılmıştır. Bulguların yorumlanmasında ise anlamlılık düzeyi 0.05 olarak alınmıştır.

\section{Bulgular}

E-öğrenmeye yönelik tutum anketi ile elde edilen verilerin analizi sonucunda aşağıdaki bulgulara ulaşı1mıştır. Bulguların sunumunda araştırma sorularına ait sıra gözetilmiştir. tutumları

Dijital okuryazarlık dersini uzaktan eğitimle alan öğrencilerin e-öğrenmeye yönelik

Dijital okuryazarlık dersini uzaktan eğitimle alan öğrencilerin e-öğrenmeye yönelik tutum anketine vermiş olduğu cevapların ortalama puanları hesaplanmış ve elde edilen tanımlayıcı istatistikler Tablo 4'te verilmiştir.

Tablo 4: E-öğrenmeye yönelik tutum puanlarının ortalama değerine ait tanımlayıcı istatistikler

\begin{tabular}{lcc}
\hline & İstatistik & Std. Sapma \\
\hline Ortalama & 3.0300 & .03191 \\
Ortanca & 3.0500 & \\
Varyans & .590 & \\
Std. Sapma & .76788 & \\
Çeyrekler arası aralık & .95 & \\
Basıklık & -.150 & .102 \\
Çarpıklık & .123 & .203 \\
\hline
\end{tabular}

Tablo 4'te verilen ortalama değerine bakıldığında $(\bar{X}=3.03)$ bu değerin Kararsızım'a karşıllk geldiği görülmektedir. Elde edilen bu değere bakıldığında dijital okuryazarlık dersini uzaktan eğitimle alan öğrencilerin e-öğrenmeye yönelik tutumlarının orta derecede olduğu bulunmuştur.

\section{Cinsiyetin e-öğrenmeye yönelik tutuma etkisi}

Dijital okuryazarlık dersini uzaktan eğitimle alan öğrencilerin e-öğrenmeye yönelik tutumları cinsiyet açısından incelenmiş ve elde edilen bulgular Tablo 5 'te verilmiştir. Tablo 5 incelendiğinde Dijital okuryazarlık dersini uzaktan eğitimle alan öğrencilerin e-öğrenmeye yönelik tutumlarının cinsiyet açısından farklılaştığı görülmektedir $(\mathrm{t}(0.03824)=2.834, \mathrm{p}<.01)$. Erkek öğrencilerin e-öğrenmeye yönelik tutumları $(\bar{X}=3.15)$, kadın öğrencilere $(\bar{X}=2.96)$ göre daha olumludur.

Tablo 5: Cinsiyetin e-öğrenmeye yönelik tutuma etkisi

\begin{tabular}{ccccccc}
\hline Cinsiyet & $\mathrm{N}$ & $\overline{\mathrm{X}}$ & $\mathrm{SS}$ & $\mathrm{sd}$ & $t$ & $p$ \\
\hline Kadın & 372 & 2.9631 & .73756 & .03824 & 2.834 & .005 \\
Erkek & 207 & 3.1504 & .80750 & .05612 & & \\
\hline
\end{tabular}

\section{Bağı bulunan ana bilim dalının e-öğrenmeye yönelik tutuma etkisi}

Dijital okuryazarlık dersini uzaktan eğitimle alan öğrencilerin bağlı bulundukları ana bilim dalı bazında e-öğrenmeye yönelik tutum ortalamaları Tablo 6'da verilmektedir. En yüksek ortalamaya sahip olan Bilgisayar ve Öğretim Teknolojileri Eğitimini $(\overline{\mathrm{X}}=3.77)$ Matematik Eğitimi $(\overline{\mathrm{X}}=3.26)$, Türkçe Eğitimi ( $\overline{\mathrm{X}}=3.06)$, Sınıf Eğitimi $(\overline{\mathrm{X}}=3.01)$, Fen Bilgisi Eğitimi $(\overline{\mathrm{X}}=2.97)$, Rehberlik ve Psikolojik Danışmanlık Eğitimi $(\overline{\mathrm{X}}=2.95)$, Yabancı Dil Eğitimi $(\overline{\mathrm{X}}=2.90)$ ve Sosyal Bilgiler Eğitimi ( $\bar{X}=2.75)$ takip etmektedir. 
Tablo 6: Tanımlayıcı istatistikler

\begin{tabular}{lcccc}
\hline Ana Bilim Dalı & $\mathrm{N}$ & $\overline{\mathrm{X}}$ & $\mathrm{SS}$ & $\mathrm{sd}$ \\
\hline Bilgisayar ve Öğretim Teknolojileri Eğitimi & 32 & 3.77 & .82846 & .14645 \\
Matematik Eğitimi & 59 & 3.26 & .61208 & .07969 \\
Türkçe Eğitimi & 61 & 3.06 & .68237 & .08737 \\
Sinıf Eğitimi & 113 & 3.01 & .79428 & .07472 \\
Fen Bilgisi Eğitimi & 86 & 2.97 & .75918 & .08186 \\
Rehberlik ve Psikolojik Danışmanlık Eğitimi & 126 & 2.95 & .79998 & .07127 \\
Yabancı Dil Eğitimi & 39 & 2.90 & .74630 & .11950 \\
Sosyal Bilgiler Eğitimi & 63 & 2.75 & .59131 & .07450 \\
\hline Toplam & 579 & 3.03 & .76788 & .03191 \\
\hline
\end{tabular}

Dijital okuryazarlık dersini uzaktan eğitimle alan öğrencilerin e-öğrenmeye yönelik tutumları öğrencisi oldukları ana bilim dalı açısından incelenmiş ve elde edilen bulgular Tablo 7'de verilmiştir. Tablo 7 incelendiğinde öğrencilerin bağlı bulundukları ana bilim dalı açısından e-öğrenmeye yönelik tutum ortalamaları arasındaki farkların anlamlı olduğu görülmektedir $(\mathrm{F}(7$, $571)=7.125, \mathrm{p}<.01)$.

Tablo 7: Bağlı bulunan ana bilim dalının e-öğrenmeye yönelik tutuma etkisi

\begin{tabular}{cccccc}
\hline Varyansın Kaynağı & Kareler Toplamı & sd & Kareler Ortalaması & $F$ & $p$ \\
\hline Gruplararası & 27.379 & 7 & 3.911 & 7.125 & .000 \\
Gruplariçi & 313.431 & 571 & .549 & & \\
\hline Toplam & 340.810 & 578 & & \\
\hline
\end{tabular}

Öğrencilerin bağlı bulundukları ana bilim dalları açısından e-öğrenmeye yönelik tutumları farklılık gösterdiği için bu farklılığın hangi gruplar arasında olduğunu belirlemek amacıyla Post Hoc testi yapılmıştır. Her ana bilim dalında eşit miktarda katılımeı olmadığından varyansların homojenliğine bakılmış ve Levene testi sonucunda homojen olmadığı $(p<0.05)$ görülmüştür. Varyanslar homojen dağılmadığı için Post Hoc testleri içerisinden Games-Hovel testi tercih edilmiş ve yapılan analiz sonucunda gruplar arasındaki farklılıklar Tablo 8'de verilmiştir. Tablo 8'de verilen Games-Howell çoklu karşılaştırma testine ait $p$ değerlerine göre Bilgisayar ve Öğretim Teknolojileri Eğitimi Ana Bilim dalının Matematik Eğitimi hariç diğer tüm ana bilim dalları ile anlamlı bir şekilde farklılık gösterdiği görülmüştür. Matematik Eğitimi ile Sosyal Bilgiler Eğitimi ana bilim dalları arasında da görülen anlamlı farklılığın haricinde diğer tüm bölümlerin kendi aralarında e-öğrenmeye yönelik tutum ortalamaları arasında anlamlı fark olmadığı tespit edilmiştir.

Tablo 8: Games-Howell çoklu karşılaştırma testine ait p değerleri

\begin{tabular}{lrrrrrrrr}
\hline Games-Howell & BÖTE & Fen Bil. & Yab. Dil & Matematik & RPD & Sinıf & Sosyal Bil. & \multicolumn{1}{c}{ Türkçe } \\
\hline BÖTE & & $\mathbf{. 0 0 0}$ & $\mathbf{. 0 0 1}$ & .067 & $\mathbf{. 0 0 0}$ & $\mathbf{. 0 0 1}$ & $\mathbf{. 0 0 0}$ & $\mathbf{. 0 0 3}$ \\
Fen Bilgisi & $\mathbf{. 0 0 0}$ & & 1.000 & .186 & 1.000 & 1.000 & .501 & .996 \\
Yabancı Dil & $\mathbf{. 0 0 1}$ & 1.000 & & .222 & 1.000 & .995 & .957 & .966 \\
Matematik & .067 & .186 & .222 & & .073 & .308 & $\mathbf{. 0 0 0}$ & .684 \\
RPD & $\mathbf{. 0 0 0}$ & 1.000 & 1.000 & .073 & & .999 & .556 & .974 \\
Sinıf & $\mathbf{. 0 0 1}$ & 1.000 & .995 & .308 & .999 & & .220 & 1.000 \\
Sosyal Bilgiler & $\mathbf{. 0 0 0}$ & .501 & .957 & $\mathbf{. 0 0 0}$ & .556 & .220 & & .139 \\
Türkçe & $\mathbf{. 0 0 3}$ & .996 & .966 & .684 & .974 & 1.000 & .139 & \\
\hline
\end{tabular}

\section{Sınıf düzeyinin e-öğrenmeye yönelik tutuma etkisi}

Dijital okuryazarlık dersini uzaktan eğitimle alan öğrencilerin e-öğrenmeye yönelik tutumları sınıf düzeyi açısından incelenmiş ve elde edilen bulgular Tablo 9'da verilmiştir. Tablo 9 incelendiğinde öğrencilerin sınıf düzeyi açısından e-öğrenmeye yönelik tutum ortalamaları arasındaki farkların anlamlı olmadığı görülmektedir $(\mathrm{F}(3.575)=2.441, \mathrm{p}>0.01)$. 
Tablo 9: Sınıf düzeyinin e-öğrenmeye yönelik tutuma etkisi

\begin{tabular}{lccccc}
\hline Varyansın Kaynağı & Kareler Toplamı & sd & Kareler Ortalaması & $F$ & $p$ \\
\hline Gruplar arası & 4.287 & 3 & 1.429 & 2.441 & .063 \\
Gruplar içi & 336.523 & 575 & .585 & & \\
\hline Toplam & 340.810 & 578 & & & \\
\hline
\end{tabular}

Genel ağırlıklı not ortalamalarının e-öğrenmeye yönelik tutuma etkisi

Dijital okuryazarlık dersini uzaktan eğitimle alan öğrencilerin e-öğrenmeye yönelik tutumları sınıf düzeyi açısından incelenmiş ve elde edilen bulgular Tablo 10' da verilmiştir. Tablo 10 incelendiğinde öğrencilerin genel ağırlıklı not ortalamalarının e-öğrenmeye yönelik tutum ortalamalarına bir etkisinin olmadığı görülmektedir $(F(1.496)=0.678, p>0.05)$.

Tablo 10: Genel ağırlıklı not ortalamasının e-öğrenmeye yönelik tutuma etkisi

\begin{tabular}{clccccc}
\hline & Model & Kareler Toplami & sd & Kareler Ortalamas & $F$ & $p$ \\
\hline \multirow{2}{*}{1} & Regresyon & .412 & 1 & .412 & .678 & .411 \\
& Kalıntı & 301.066 & 496 & .607 & & \\
\cline { 2 - 7 } & Toplam & 301.477 & 497 & & & \\
\hline
\end{tabular}

\section{Dijital okuryazarlık dersi ara sınav notunun e-öğrenmeye yönelik tutuma etkisi}

Dijital okuryazarlık dersini uzaktan eğitimle alan öğrencilerin e-öğrenmeye yönelik tutumları öğrencilerin bu dersin ara sınavından almış oldukları sınav notu açısından incelenmiş ve elde edilen bulgular Tablo 11'de verilmiştir. Tablo 11 incelendiğinde öğrencilerin bu dersin ara sınavından almış oldukları notların e-öğrenmeye yönelik tutum ortalamalarına pozitif yönde etki ettiği görülmektedir $(\mathrm{F}(1,550)=8.741, \mathrm{p}<0.05)$.

Tablo 11: Dijital okuryazarlık dersi ara sınav notunun e-öğrenmeye yönelik tutuma etkisi

\begin{tabular}{clccccc}
\hline & Model & Kareler Toplam1 & sd & Kareler Ortalamas1 & $F$ & $p$ \\
\hline \multirow{4}{*}{1} & Regresyon & 5.021 & 1 & 5.021 & 8.741 & $.003^{\text {b }}$ \\
& Kalınt1 & 315.923 & 550 & .574 & & \\
\cline { 2 - 7 } & Toplam & 320.944 & 551 & & & \\
\hline
\end{tabular}

\section{Tartışma, Sonuç ve Öneriler}

Dijital okuryazarlık dersini uzaktan eğitimle alan öğrencilerin e-öğrenmeye yönelik tutumları "Kararsızım" seviyesindedir. Bizzat uzaktan eğitim almış öğrencilerden ortalamanın üzerinde bir tutum beklenirken orta seviyede bir tutum ile karşılaşılmış olması alınan eğitimin hedeflerine beklenen düzeyde ulaşılmadığını göstermektedir. Öğrencilerden beklenen olumlu tutuma sahip olmamalarının nedeni dijital okuryazarlık ders içeriklerinin öğrencilerin seviyesine uygun olmamasından kaynaklandığı düşünülebilir. Ateş ve Altun (2008), uzaktan eğitim deneyimi yaşamış öğrenciler üzerinde yaptıkları çalışmada benzer şekilde öğrencilerin uzaktan eğitime karş1 tutumlarının kararsız seviyeye yakın olduğu sonucuna ulaşmışlardır. Literatürde genelde öğretmenlerin ve öğrencilerin e-öğrenmeye yönelik tutumlarının olumlu veya olumluya yakın orta düzeyde olduğu yönünde sonuçlara da rastlamak mümkündür (Çoban \& Tezci, 2019; Dikbaş, 2006; Şentürk, 2016).

Öğrencilerin e-öğrenmeye yönelik tutumlarında cinsiyet açısından istatistiksel olarak anlamlı bir farklılık olduğu ve bu farklılığın erkek öğrencilerin lehine olduğu sonucuna varılmıştır. Thakkar ve Joshi (2017), yapmış oldukları çalışmada öğrencilerin e-öğrenmeye yönelik tutumlarında cinsiyet açısından bir farklılığın olmadığı sonucuna varmışlardır.

Öğrencilerin bağlı bulundukları ana bilim dalları ile e-öğrenmeye yönelik tutumları arasında da anlamlı bir ilişki tespit edilmiştir. Müfredatında öğretim tasarımı ve bilgisayarın eğitim ortamında farklı şekillerde kullanımına yönelik dersler barındıran Bilgisayar ve Öğretim Teknolojileri Eğitimi öğrencilerinin e-öğrenmeye yönelik tutumlarının diğer bölümlerden olumlu olduğu sonucuna 
varılmıştır. E-öğrenmeye yönelik ortalama puanlara göre sıralama yapılınca sayısal içerikli bölümlerin üst tarafta yer alması bu bölümlerin e-öğrenmeye yönelik tutumunun sözel bölümlere göre daha olumlu olduğu söylenebilir. Dijital okuryazarlık dersini her bölümün eşit şartlarda aldığında sonucun farklı olduğu göz önüne alınınca sözel bölümlerde beklenen başarıyı elde etmek için bu bölümleri destekleyici etkinlikler yapmanın faydalı olacağı düşünülmektedir. Öğrencilerin eöğrenmeye yönelik tutumlarının incelendiği bir başka çalışma ise öğrencilerin almış oldukları bilişim temelli eğitim ve bilgisayar becerilerinin e-öğrenmeye yönelik tutumlarının önemli bir yordayıcısı olduğunu göstermiştir (Rhema \& Miliszewska, 2014).

Öğrencilerin e-öğrenmeye yönelik tutumu sınıf düzeyleri açısından farklılık göstermemektedir. Benzer şekilde Rhema ve Miliszewska (2014) da yapmış oldukları çalışmada yaş veya sınıf düzeyleri açısından öğrencilerin e-öğrenmeye yönelik tutumuna etki etmediği sonucuna varmışlardır. Her sınıf düzeyinde benzer tutumlara rastlanmasının sebebi, sınıf düzeyinin artmasının e-öğrenme deneyimini artıran bir etken olmaması olabilir.

Öğrencilerin e-öğrenmeye yönelik tutumu genel ağırlıklı not ortalaması açısından farklılık göstermemektedir. Akademik başarının yüksek olması e-öğrenmeye yönelik tutumun da yüksek olacağı anlamına gelmemektedir. E-öğrenmeye yönelik olumlu tutum geliştirmenin, bu konuda yaşanmış başarılı tecrübelere dayandığ düşünülmektedir. Başka alanlarda elde edilen akademik başarının e-öğrenmeye yönelik tutuma doğrudan bir etkisinin olmadığı söylenebilir.

Dijital okuryazarlık dersinin ara sınav notları ile öğrencilerin e-öğrenmeye yönelik tutumları arasında olumlu bir ilişki bulunmaktadır. Genel ağırlıklı not ortalamasının yüksek olmasının e-öğrenmeye yönelik tutuma bir etkisinin olmamasına rağmen dijital okuryazarlık dersinin ara sınav notunun yüksek olmasının etkili olduğu görülmektedir. $\mathrm{Bu}$ dersten alınan ara sınav notunun öğrencinin dijital okuryazarlık dersindeki akademik başarısını temsil etmesi, bu dersin içeriğinde yer alan uzaktan eğitim ve internet destekli eğitim konularında da bilgi sahibi olduklarını gösterdiği düşünülebilir.

Çalışmadan elde edilen sonuçlar doğrultusunda aşağıdaki önerilerde bulunulabilir:

- Yükseköğretimde yaşanan dijital dönüşüm sürecinde başarı elde edilmesinin bu yönde geliştirilecek olumlu tutumlara bağlı olduğu söylenebilir. Çalışmadan elde edilen sonuçlara bakıldığında e-öğrenmeye yönelik orta derecede tutum sahibi olan öğrenciler için destekleyici eğitim ve seminerler verilebilir.

- Bu çalışmada sadece öğrencilerin e-öğrenmeye yönelik tutumları araştırılmıştır. Yaşanan dijital okuryazarlık dersi deneyimi konusunda öğrencilerin görüşlerinin alındığ 1 nitel çalışmalar yapılabilir.

- Dijital okuryazarlık ders içeriklerinin öğrenci potansiyeli göz önünde bulundurularak hazırlanması önerilebilir.

- E-öğrenmeye yönelik olumlu tutum geliştirmek için yükseköğretimin her programında içeriği uygun olan dersler uzaktan eğitimle verilebilir. 


\section{Kaynakça}

Acar, Ç. (2015). Anne ve babaların ilkokul ortaokul ve lise öğrencisi çocuklarl ile kendilerinin dijital okuryazarlıklarına ilişskin görüşleri. Ankara: Ankara Üniversitesi.

Ateş, A., \& Altun, E. (2008). Bilgisayar öğretmeni adaylarının uzaktan eğitime yönelik tutumlarının çeşitli değişkenler açısından incelenmesi. Gü, Gazi Eğitim Fakültesi Dergisi, $28(3), 125-145$.

Atkins, D., Brown, J., \& Hammo, A. (2007). A review of the Open Educational Resources (OER) movement: achievements, challenges, and new opportunities. The William and Flora Hewlett Foundation.

Balyer, A., \& Öz, Ö. (2018). Academicians' views on digital transformation in education. International Online Journal of Education and Teaching (IOJET), 5(4), 809-830.

Bates, A. W. (2018). Teaching in a digital age: Guidelines for designing teaching and learning.

Castells, M. (2005). Enformasyon çağı: Ekonomi, toplum ve kültür. A $\breve{g}$ toplumunun Yükselişi. (E. Kılıç, Çev., Cilt I). İstanbul Bilgi Üniversitesi Yayınları.

Clark, D. (2002). Psychological myths in e-learning. Medical Teacher, 24(6), 598-604. https://doi.org/10.1080/0142159021000063916

Çoban, H., \& Tezci, E. (2019). Farklı değişkenler açısından öğretmenlerin e-öğrenmeye yönelik tutumlarının incelenmesi. ICHES International Humanities and Educational Sciences Congress, (s. 130-150). İzmir.

Dede, C. (2005). Planning for neomillennial learning styles. Educause Quarterly, 28(1), 7-12.

Demiral, S. (2018). Dijital teknoloji aracılı̆̆ıyla çocuk özneleşmesinin olanakları. Doğu Batı, 21(86), 13-37.

Demirel, M. (2009). Yaşam boyu öğrenme ve teknoloji. 9th International Educational Technology Conference (IETC2009), (s. 696-703). Ankara.

Dikbaş, E. (2006). Öğretmen adaylarının e-ögrenmeye yönelik tutumlarının incelenmesi. Dokuz Eylül Üniversitesi, Eğitim Bilimleri Enstitüsü.

Duran, E., \& Özen, N. (2018). Türkçe derslerinde dijital okuryazarlık. Türkiye Ĕ̈itim Dergisi, 3(2), $31-46$.

Eshet, Y. (2002). Digital literacy: A new terminology framework and its application to the design of meaningful technology-based learning environments. Association for the Advancement of Computing in Education (AACE).

Eshet-Alkalai, Y. (2004). Digital literacy: A conceptual framework for survival skills in the digital era. Journal of educational multimedia and hypermedia, 13(1), 93-106.

Fırat, M., \& Güney, Y. (2020). Açıköğretim'in toplumda dijital dönüşüm işlevi. Açıköğretim Uygulamaları ve Araştırmaları Dergisi, 6(1), 53-62.

Gefen, D., \& Straub, D. W. (1997). Gender differences in the perception and use of e-mail: An extension to the technology acceptance moedel. MIS Quarterly, 21(4), 389-400.

George, D., \& Mallery, M. (2010). SPP for Windows step by step: A simple guide and reference (10 b.). Boston: Pearson.

Gilster, P. (1997). Digital Literacy. New York: John Wiley. 
Haznedar, Ö. (2012). Üniversite öğrencilerinin bilgi ve iletişim teknolojileri becerilerinin ve eögrenmeye yönelik tutumlarının farklı değişkenler açısından incelenmesi. Dokuz Eylül Üniversitesi Eğitim Bilimleri Enstitüsü.

Karabacak, Z. İ., \& Sezgin, A. A. (2019). Türkiye'de dijital dönüşüm ve dijital okuryazarlık. Türk İdare Dergisi, 91(488), 319-343.

Karasakaloğlu, N., \& Saracaloğlu, A. S. (2009). Sınıf öğretmeni adaylarının Türkçe derslerine yönelik tutumları, akademik benlik tasarımları ile başarıları arasındaki ilişki. Yüzüncü Yıl Üniversitesi, Eğitim Fakültesi Dergisi, 6(1), 343-362.

Krishnakumar, R., \& Kumar, R. M. (2011). Attitude of teachers of higher education towards eLearning. Journal of Education and Practice, 2(4), 48-53.

Martin, A. (2005). DigEuLit - a European framework for digital literacy: A progress report. Journal of e-Literacy, 2(2), 130-136.

McLuhan, M., \& Powers, B. R. (2001). Global köy: 21. yüzyılda yeryüzü yaşamında ve medyada meydana gelecek dönüşümler. (B. Ö. Düzgören, Çev.) İstanbul: Scala Yayıncılık.

Metin, M. (2015). Kuramdan Uygulamaya Eğitimde Bilimsel Araştırma Yöntemleri (2 b.). Pegem Akademi.

Prensky, M. (2001). Digital natives, digital immigrants: do they really think differently? On the Horizon, 9(6), 1-6.

Rhema, A., \& Miliszewska, I. (2014). Analysis of student attitudes towards e-learning: The case of engineering students in Libya. Issues in Informing Science and Information Technology, 11, 169-190. https://doi.org/10.28945/1987

Şentürk, C. (2016). Öğretmenlerin e-öğrenmeye yönelik tutumlarının farklı değişkenler açısından incelenmesi. Uluslararası Sosyal Araştırmalar Dergisi, 9(43), 1501-1511.

Tabachnick, B., \& Fidell, L. (2013). Using multivariate statistics (6 b.). Boston: Pearson.

Tapscott, D. (2009). Growing up digital: How the net generation is changing your world. McGraw Hill.

Taşkıran, A. (2017). Dijital çağda yükseköğretim. Açıköğretim Uygulamaları ve Araştırmaları Dergisi, 3(1), 96-109.

TDK. (2020). Türk Dil Kurumu. 07 01, 2020 tarihinde Sözlük: https://sozluk.gov.tr/

Thakkar, S., \& Joshi, H. (2017). Students' attitude towards e-learning. International Journal of Advance Engineering and Research Development, 4(11), 209-213. https://doi.org/10.1007/s10639-020-10152-0

Tuomi, I. (2013). Open educational resources and the transformation. European Journal of Education, 48(1), 58-78. https://doi.org/10.1111/ejed.12019

Wilkinson, A., Roberts, J., \& While, A. (2010). Construction of an instrument to measure student information and communication technology skills, experience and attitudes to e-learning. Computers in Human Behavior, 26, 1369-1376. https://doi.org/10.1016/j.chb.2010.04.010

Yakovenko, I., Kulumbetova, L., Subbotina, I., Zhanibekova, G., \& Bizhanova, K. (2019). The blockchain technology as a catalyst for digital transformation of education. International Journal of Mechanical Engineering and Technology, 10(1), 886-897.

Yıldız-Aybek, H. (2017). Üniversite 4.0'a geçiş süreci: kavramsal bir yaklaşım. Açıköğretim Uygulamaları ve Araştırmaları Dergisi, 3(2), 164-176. 